\title{
PREPARATION OF POWDER FROM BROWN SEAWEED (SARGASSUM PLAGYOPHYLLUM) BY FREEZE-DRYING WITH MALTODEXTRIN AS A STABILIZER
}

\author{
EFFIONORA ANWAR*, HILMIA ERIANTO, KURNIA SARI SETIO PUTRI
}

\author{
Department of Pharmaceutical Technology, Faculty of Pharmacy, Universitas Indonesia, Depok, 16424, Indonesia. \\ Email: effionora.anwar@farmasi.ui.ac.id
}

Received: 01 April 2018, Revised and Accepted: 28 October 2018 and 01 November 2018

\section{ABSTRACT}

Objective: The aim of this study was to prepare powder from liquid extract with maltodextrin dextrose equivalent 10-15 as a stabilizer using a freezedrying method to maintain stability during drying process and extend storage time.

Methods: Powders were prepared for four formulas: F1 (without maltodextrin), F2 (2.5\% maltodextrin), F3 (5\% maltodextrin), and F4 (10\% maltodextrin). Powder from the four formulas was characterized by its phlorotannin concentration, antioxidant activity, water content, morphology, particle size distribution, $\mathrm{pH}$, and organoleptic activities.

Results: F4 was the best formula because it contained the highest phlorotannin concentration (113.06 \pm 1.36$)$ or $0.25 \%$, highest percentage of inhibition concentration $_{50}\left(\mathrm{IC}_{50}\right)(4.06 \%$ at a concentration of $5000 \mathrm{ppm})$, and lowest water content (5.16\%); moreover, in a stability test, F4 exhibited a more stable phlorotannin concentration and lower water content than $\mathrm{F} 1$, with an optimal storage temperature of $4^{\circ} \mathrm{C}$.

Conclusion: Maltodextrin can improve the stability bioactive compounds during the freeze-drying process and storage time.

Keywords: Phlorotannin, Freeze-drying, Sargassum plagyophyllum, Maltodextrin dextrose equivalent 10-15.

(C) 2018 The Authors. Published by Innovare Academic Sciences Pvt Ltd. This is an open access article under the CC BY license (http://creativecommons. org/licenses/by/4. 0/) DOI: http://dx.doi.org/10.22159/ijap.2018.v10s1.77

\section{INTRODUCTION}

Seaweed is a component of the ecosystem along the coasts of Indonesia [1]. It can be divided into green seaweed or Chlorophyta, brown seaweed or phaeophyta, and red seaweed or Rhodophyta [2]. Brown seaweed has a higher level of bioactive compounds than the two other types [3]. One type of brown seaweed found along the coast of Indonesia is Sargassum spp., such as Sargassum plagyophyllum.

Among many bioactive compounds contained in brown seaweed including Sargassum sp., antioxidants are particularly interesting because they are key compounds in treating various degenerative diseases and for preventing aging. Natural antioxidants in seaweed come from phlorotannin compounds, ascorbic acid, tocopherol, and carotenoid. Various studies have also revealed that phlorotannin is an antioxidant compound that plays the most important role in photoprotection in seaweed [4].

Phlorotannin is a polyphenol compound that is produced by the polymerization of a phloroglucinol monomer (1,3,5-trihydroxy benzene). As an antioxidant, phlorotannin has 10-100 times better activity against free radicals than flavonoids found in terrestrial plants [5]. However, the antioxidant activity of phlorotannin compounds and their use as food dyes are strongly influenced by their stability. Phlorotannin stability, such as that of the compounds polyphenols, is affected by $\mathrm{pH}$, metal ions, light, temperature, oxygen, and enzyme activity [6-9]. Therefore, to maintain the antioxidant levels and physiological effects of phlorotannin compounds during the drying and storage process, a stabilizer is used, a commonly used example of which is maltodextrin.

Maltodextrin is a polymer composed of d-glucose units with dextrose equivalent $(D E)<20$, which is used as a coating agent [10]. Maltodextrin is known to have low permeability to oxygen, thereby preventing oxidation of the active substance and increasing its stability during storage. The use of maltodextrin could, thus, have a positive effect on the stability of phlorotannin compounds during storage, preventing or minimizing their oxidation, which may affect the decrease in phlorotannin content and antioxidant activity.

Besides using maltodextrin as a stabilizer, freeze-drying is used in the drying process to improve the stability of phlorotannins. This is because the use of a drying temperature below room temperature is suitable for heat-sensitive compounds such as polyphenol compounds [11]. Phlorotannins are members of the polyphenol compounds, so their conversion into powder using freeze-drying techniques can prevent their degradation by drying at high temperatures, as in the dry spray and oven method.

Therefore, to maintain phlorotannin stability against a high temperature in the drying process and against oxidation during storage, this study used $S$. plagyophyllum extract powder with a freeze-drying technique using maltodextrin as a stabilizer. Then, the stability and characteristics of S. plagyophyllum extract powder were investigated for 8 weeks of storage.

\section{MATERIALS AND METHODS}

Research method

S. plagyophyllum simplicia setup

Brown seaweed S. plagyophyllum (Mertens) J.G. Agardh. was taken directly from Binuangeun Beach, Lebak, Banten. The samples were then washed and dried by aeration for about 4 days [12]. The simplicia was then identified at the Oceanographic Institute of the Indonesian Institute of Sciences, Ancol, North Jakarta.

S. plagyophyllum (Mertens) J.G. Agardh. extraction

The simplicia were cut into small pieces, weighed to $600 \mathrm{~g}$, put into a brown bottle, and extracted by maceration for $24 \mathrm{~h}$, followed by stirring at room temperature [13]. The extract was filtered with filter paper, 
after which the filtrate was obtained and the residual residue was discarded. The filtrates obtained from four bottles were then combined.

\section{Characterization of $S$. plagyophyllum liquid extract}

Liquid extracts were identified organoleptically by visual/olfactory analysis, including of their color and odor. The $\mathrm{pH}$ of the liquid extract was measured using a $\mathrm{pH}$ meter.

Determination of phlorotannin S. plagyophyllum liquid extract levels Determination of phlorotannins content in the liquid extract was performed by reacting the extract filtrate with Folin-Ciocalteu solution and $7.5 \%$ sodium carbonate solution, followed by incubation at room temperature in the dark for $70 \mathrm{~min}$. The absorption of the solution was measured using ultraviolet-visible spectrophotometry at a wavelength of $707 \mathrm{~nm}$. The levels were calculated by comparing the uptake of the extract with the standard uptake of phloroglucinol [13].

\section{Determination of $S$. plagyophyllum liquid extract antioxidant activity}

The determination of antioxidant activity was performed using 2,2-diphenyl-1-picrylhydrazyl (DPPH) as a free radical. An extract weighing a total of $5 \mathrm{~g}$ was put into a $10-\mathrm{mL}$ volumetric flask, ethanol p.a. was added until the limit marks of the volumetric flask, forming the main solution with a concentration of 500,000 ppm. The formed solution was sonicated for $60 \mathrm{~min}$, introduced into a centrifugation tube, and centrifuged at $1500 \mathrm{rpm}$ for $4 \mathrm{~min}$ [14]. The main solution was then diluted to six different concentrations. Subsequently, each solution was incubated in the dark at a temperature of $28^{\circ} \mathrm{C}$ (room temperature) for $30 \mathrm{~min}$, followed by measurement at a wavelength of $516 \mathrm{~nm}$. Then, its inhibition concentration ${ }_{50}\left(\mathrm{IC}_{50}\right)$ was measured using the following formula of a linear regression equation: $y=a+b x$, with $y$ being the average percent inhibition and $x$ being the concentration of each test solution. Ascorbic acid was used for comparison, with the same treatment applied to the samples. The resulting linear regression equation was used to calculate the $\mathrm{IC}_{50}$ value, namely, the sample concentration required to inhibit $50 \%$ of the concentration of free radical DPPH. The percentage DPPH inhibition of each sample series solution was calculated by dividing (blank uptake-sample uptake) with blank uptake then times $100 \%$.

While the antioxidant activity represented by the $\mathrm{IC}_{50}$ values was calculated using the obtained linear regression equation, the $y$ value is $50 \%$ inhibition so that $y$ is changed to 50 .

\section{Making S. plagyophyllum extract powder}

The powder consisted of four different formulations, namely without maltodextrin (F1), as well as with maltodextrin DE 10-15 2.5\% (F2), $5 \%$ (F3), and 10\% (F4). Each formulation was dried by multilevel drying as shown in Table 1 . First, it was inserted into a freezer at $-20^{\circ} \mathrm{C}$ fitted to the FDU 1200 Eleya freeze-drying tool and dried to form a stable solid mass for about $72 \mathrm{~h}$ at $-45.5^{\circ} \mathrm{C}$ under pressure of $15.3 \mathrm{pa}$. The dried powder that was still present in the drying container was then taken and dredged. Subsequently, each powder formulation was disrupted with a blender, weighed, and stored in a glass container that was tightly sealed [15].

\section{Physical characterization of powdered $S$. plagyophyllum liquid} extract

Organoleptic powders can be identified by their odor, color, and texture. Here, the morphology of the powder was observed by scanning electron microscopy (EVO MA 10; Carl Zeiss, United States) at 14 KV EHT and an secondary electron (SE) detector SE. The particle size distribution of Sargassum powder was measured using a 2000 Mastersizer tool from Malvern. The water level of the powder was measured using a moisture analyzer at $105^{\circ} \mathrm{C}$. The $\mathrm{pH}$ of the powder was measured using a $\mathrm{pH}$ meter for $1 \mathrm{~g}$ of powder dispersion in $10 \mathrm{~mL}$ of aquadest.

\section{Test of phlorotannin levels in powder of liquid S. plagyophyllum} extract

Phlorotannin levels were tested using the Folin-Ciocalteu method. Powder of each of F1, F2, F3, and F4 was weighed to $300 \mathrm{mg}$ and put into a $10-\mathrm{mL}$ volumetric flask, aquadest was added to adjust the volume until limit marks of the volumetric flask, followed by shaking to homogeneity. The determination of phlorotannin content was performed as for the liquid extract.

\section{Antioxidant activity test of powdered S. plagyophyllum liquid} extract

The antioxidant activity of the extract was tested by measuring the preventive activity against the free radical DPPH. A number of powders in each formulation of F1, F2, F3, or F4 were weighed and added with volume of ethanol p.a. to the limit of volumetric flask until the desired concentration was obtained, followed by performance of the antioxidant activity test the same as for the liquid extract.

\section{Powder stability test of liquid S. plagyophyllum extract}

Stability tests including phlorotannin and water levels were performed fortnightly for 8 weeks. These tests were carried out at three temperature storage conditions: $42^{\circ} \mathrm{C}, 282^{\circ} \mathrm{C}$, and $402^{\circ} \mathrm{C}$. The test was performed on $\mathrm{F} 4$, which has the highest phlorotannin content. F1 was also included for comparison between powders without and with maltodextrin

\section{RESULTS}

\section{Simplicia setup}

Physical comparison of fresh S. plagyophyllum (Mertens) J.G. Agardh. and its dried form are shown in Fig. 1. From about $30 \mathrm{~kg}$ of fresh S. plagyophyllum (Mertens) J.G. Agardh. after drying, only $\sim 3 \mathrm{~kg}$ of simplicia was obtained, giving a yield of $10 \%$.

The S. plagyophyllum (Mertens) J.G. Agardh. was further extracted, resulting in extraction filtrate which was brown. The liquid extract had a dark brown color and a distinctive smell as shown in Fig. 2.

\section{Test of the acidity of liquid $S$. plagyophyllum extract}

The test results showed that the $\mathrm{pH}$ of the liquid extract was about 7 or neutral.

\section{Determination of phlorotannin levels of liquid S. plagyophyllum extract}

Regarding the optimization of the incubation time, it was found that 70 min was the optimal period for incubation because that duration was associated with higher absorption of standard phloroglucinol solution than the other times $(10,20,30,40,50,60,80$, and $90 \mathrm{~min})$. In the calibration curve, a linear regression equation of $\mathrm{y}=-0.0936+0.0043 \mathrm{x}$ was obtained, with an $r=0.99939$ to be used for the determination of phlorotannin levels in liquid extract and powder. Thereafter, the fluorothene content in the liquid extract was determined as mg of phloroglucinol per gram of simplicia and mg of phloroglucinol per

Table 1: Extracted S. plagyophyllum powder formulation

\begin{tabular}{lllll}
\hline Material & Formula & & \\
\cline { 2 - 5 } & F1 (without maltodextrin) & F2 (MD 2.5\%) & F3 (MD 5\%) & F4 (MD 10\%) \\
\hline Extract (g) & 400 & 400 & 400 & 400 \\
Maltodextrin DE 10-15 (g) & - & 10 & 20 & 40 \\
Coating ratio: Extract & - & $1: 40$ & $1: 20$ & $1: 10$ \\
\hline
\end{tabular}

DE: Dextrose equivalent 


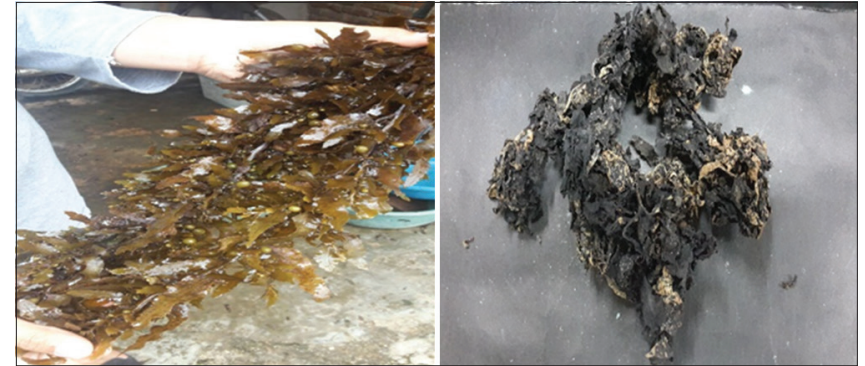

Fig. 1: Fresh seaweed (left) and simplicia (right)

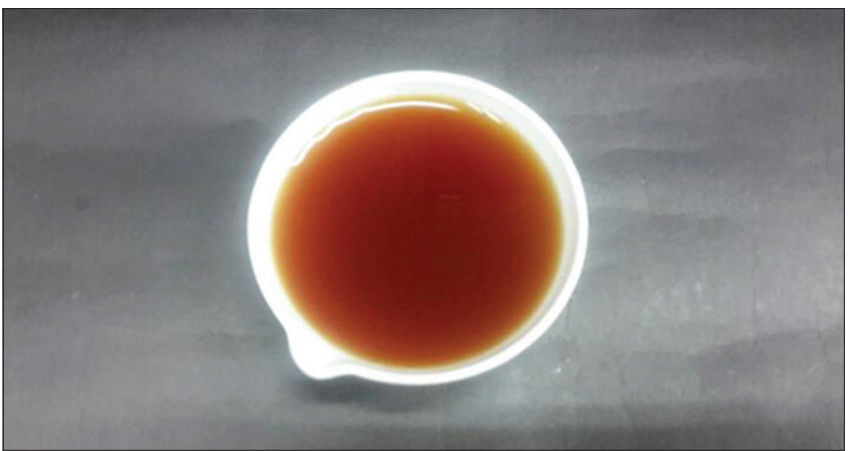

Fig. 2: Sargassum plagyophyllum extract

gram of liquid extract. The average liquid extract level of the three tests was $2390.02 \mathrm{mg}$ phloroglucinol per gram of simplicia or $0.24 \mathrm{mg}$ of phloroglucinol per gram of liquid extract.

\section{Determination of antioxidant activity of $S$. plagyophyllum liquid} extract

The test on the antioxidant activity of the extract was performed by making a solution of DPPH using ethanol solvent p.a. that generated maximum wavelength at $516 \mathrm{~nm}$. This test used ascorbic acid as a positive control for comparison with the activities of antioxidant liquid extract and dried powder. The ascorbic acid antioxidant activity test was performed in duplicate, and an $\mathrm{IC}_{50}$ of ascorbic acid of $3.11 \pm 0.02 \mathrm{ppm}$ was obtained. The antioxidant test of liquid extract was carried out at six selected concentrations of 500,1000, 1500, 2000, 2500, and $3000 \mathrm{ppm}$; the results showed that only limited inhibition occurred, which did not reach $50 \%$, but at higher concentration extracts, namely $5000 \%, 25,000 \%$, and $50,000 \%$, the inhibition of DPPH by the extract was lower than at the concentration of $3000 \mathrm{ppm}$. Therefore, for the liquid extract, $\mathrm{IC}_{50}$ calculation cannot be performed because the obtained results are not relevant to the test.

\section{Production of $S$. plagyophyllum extract powder}

The largest amount of powder was produced for F4, followed by F3, F2, and F1 in this order (Table 2).

The S. plagyophyllum extract powder in each formulation has a distinctive odor, as in the extract. The morphological view of the powder is shown in Fig. 3.

Size distribution of particle powder test of $S$. plagyophyllum liquid extract

The results of the measurement show that the greater the maltodextrin percentage used in the powder formulation, the larger the particle size of the powder. However, there are exceptions, in that the result for F4 was smaller than for F3, although with no significant difference between them (Table 3).

\section{Water level test of powdered S. plagyophyllum liquid extract}

The resulting water level has been identified in the requirements of powdered water content or not. For natural materials, the water level

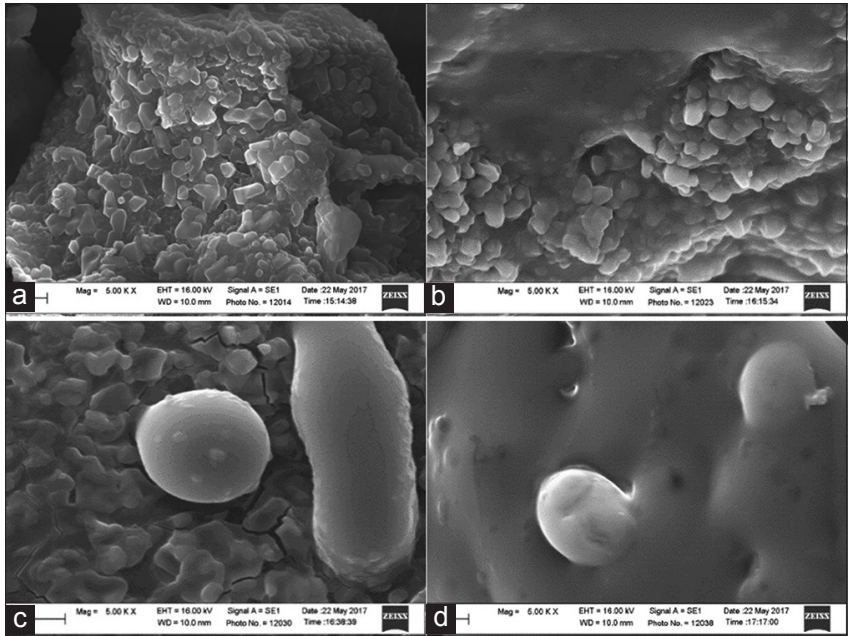

Fig. 3: Scanning electron microscopy microphotographs of powder: (a) F1, (b) F2, (c) F3, and (d) F4 at 5000× magnification

Table 2: Freeze-dried powder

\begin{tabular}{llll}
\hline Formulation & $\begin{array}{l}\text { Amount of } \\
\text { extract (g) }\end{array}$ & $\begin{array}{l}\text { Amount of } \\
\text { maltodextrin (g) }\end{array}$ & $\begin{array}{l}\text { Amount of dried } \\
\text { frozen powder (g) }\end{array}$ \\
\hline F1 & 400 & 0 & 5.91 \\
F2 & 400 & 10 & 15.13 \\
F3 & 400 & 20 & 25.39 \\
F4 & 400 & 40 & 44.58 \\
\hline
\end{tabular}

Table 3: Distribution of freeze-dried powder particles

\begin{tabular}{ll}
\hline Size particle distribution $(\boldsymbol{\mu m})$ & \\
\hline Formula & $\mathrm{d} 90$ \\
F1 & 149.215 \\
F2 & 325.397 \\
F3 & 341.940 \\
F4 & 336.536 \\
\hline
\end{tabular}

that fulfills the requirements is not $>10 \%$. The water levels of the four formulas are shown in Table 4

Tests of acidity of powdered S. plagyophyllum extract

Each powder solution of the four different formulations as used for the $\mathrm{pH}$ assays could be completely dissolved. This test was performed in triplicate (Table 5).

Test of phlorotannin powder levels of liquid S. plagyophyllum extract

The concentrations of phlorotannin in the four powder formulas are shown in Table 6. Of the four formulas, the highest phlorotannin content was identified in F4.

Antioxidant activity test of powdered $S$. plagyophyllum liquid extract

The percentage inhibition obtained from F2, F3, and F4 did not reach $50 \%$, so $\mathrm{IC}_{50}$ could not be calculated. As the percentage inhibition of each formula differed, to compare antioxidant activities, the percentage inhibition of each formulation at a concentration of $5000 \mathrm{ppm}$ was used, as shown in Table 7.

There was a test for level stability of powdered S. plagyophyllum liquid extract. F1 and F4 moisture tests showed that F1 had a higher water level than F4 at all lead temperatures. In both F1 and F4, the highest water level occurred during storage at a temperature of $4^{\circ} \mathrm{C}$, followed by temperatures of $28^{\circ} \mathrm{C}$ and $40^{\circ} \mathrm{C}$ (Table 8). 
Test of phlorotannin level stability of powdered liquid S. plagyophyllum extract

The results of the stability test showed that, in F1, on 8 weeks of storage, stability had decreased significantly compared with that for F4. The phlorotannin levels of $\mathrm{F} 1$ and F4 powders are given in two different units, namely mg phloroglucinol per number of powders produced and percentage (\%), as shown in Tables 9 and 10, respectively.

\section{DISCUSSION}

\section{Simplicia setup}

Drying was performed by aeration. This method was chosen because this drying method can produce phlorotannin compounds for seaweed better than exposure to direct sunlight or use of an oven. This is because heat can affect the level of phlorotannin produced. The best method of drying to optimize the stability of seaweed phlorotannin compounds is by aeration, followed by use of an oven and least effectively exposure to direct sunlight [9]. About $30 \mathrm{~kg}$ of fresh S. plagyophyllum (Mertens) J.G. Agardh. only produced $3 \mathrm{~kg}$ of simplicia, so the yield was $10 \%$ (Fig. 1).

\section{S. plagyophyllum (Mertens) J.G. Agardh. extraction}

The extraction filtrate was brown. This filtrate was used for the evaluation of the extract and the creation of powder.

\section{Organoleptic test of liquid S. plagyophyllum extract}

The liquid extract was dark brown in color and had a distinctive (fishy) smell. The brown color was obtained because of the seaweed S. plagyophyllum (Mertens) J.G. Agardh. being a brown seaweed with a brown pigment [1].

\section{Test of acidity of liquid S. plagyophyllum extract}

This test was performed to determine whether there was any change of $\mathrm{pH}$ between the liquid extract before drying and the powder obtained after drying using the freeze-dryer tool, for the four established formulas. The test results showed that the $\mathrm{pH}$ of the liquid extract was around 7 or neutral. This is because liquid extracted in aqua demineralisation solvent has a $\mathrm{pH}$ of 7 (according to $\mathrm{CoA}$ ), resulting in an average $\mathrm{pH}$ obtained from three tests of $7.82 \pm 0.08$.

Table 4: Water levels of freeze-dried powders

\begin{tabular}{ll}
\hline Formulation & Water level (\%) \\
\hline F1 & 6.81 \\
F2 & 6.34 \\
F3 & 5.81 \\
F4 & 5.16 \\
\hline
\end{tabular}

Table 5: Acidity of powder and liquid extracts

\begin{tabular}{ll}
\hline Formula & Acidity (pH) \\
\hline F1 & $10.66 \pm 0.01$ \\
F2 & $9.93 \pm 0.01$ \\
F3 & $9.59 \pm 0.01$ \\
F4 & $9.41 \pm 0.02$ \\
Extract & $7.82 \pm 0.02$ \\
\hline
\end{tabular}

Determination of phlorotannin level of liquid S. plagyophyllum extract

From the optimization of the incubation time, it was found that $70 \mathrm{~min}$ was the optimum time for incubation. Subsequently, a calibration curve was produced, which was used to determine the phlorotannin content in the liquid extract calculated as mg phloroglucinol per gram of simplicia and mg phloroglucinol per gram of liquid extract. The average liquid extract level of the three tests was $2.39 \pm 0.02 \mathrm{mg}$ phloroglucinol per gram of simplicia or $0.24 \mathrm{mg}$ of phloroglucinol per gram of liquid extract. This latter value is low because liquid extract has not been used to attempt to separate the phlorotannin compound from other compounds in the simplicia, which also occurs during the extraction process, so, the extract contains phlorotannin. Brown seaweed is known to contain not only polar compounds in the form of phlorotannins but also other polar compounds, which can be carried by aquadest (solvent used for extraction). This leads to the result of the test containing only a small amount of phlorotannin.

\section{Making S. plagyophyllum extract powder}

The largest amount of powder was produced by F4, followed by F3, F2, and F1 in this order. If the same amount of extract is used, then the amount of powder produced is proportional to the amount of maltodextrin used in the formulation. An increase in the amount of maltodextrin used in the formula will increase the amount of solids or powders produced. An increase in the amount of powder in line with an increase in the amount of maltodextrin used relates to the nature of maltodextrin as a drying agent and may increase the amount of solids in the resulting powder [15].

Organoleptic test of powdered liquid S. plagyophyllum extract The powder in each formulation has a distinctive odor, as in the extract. The less maltodextrin used, the more distinctive the odor. Meanwhile, the color of the powder appeared to become more faded with the increasing amount of maltodextrin used.

Test of the water level of powdered S. plagyophyllum liquid extract The measurements showed that the powder with the highest water level was F1, followed by F2, F3, and F4. The water level was higher in formulations with less maltodextrin. This is because the use of maltodextrin in the formulation can decrease the water level as well as the hygroscopicity of the dried powder in the freezing process. Maltodextrin is a drying agent that can increase the amount of solid (powder) and decrease the amount of free water during the drying process so that the resulting powder has less water than the dried powder without maltodextrin [15].

The powdered water level of natural substances is not $>10 \%$, and since all powder formulas of F1, F2, F3, and F4 had a water level of $>10 \%$, all formulas meet the water level condition.

Test of acidity of powdered S. plagyophyllum liquid extract

Each powder solution of the four different formulations for $\mathrm{pH}$ assays could be completely dissolved. When compared with the $\mathrm{pH}$ of the extract solution before the drying process, all solutions derived from the four different formulas had a more basic $\mathrm{pH}$ than the extract solution. This is because the drying process attracts acidic substances into the solution to be dried, so the dried powder will have more alkaline properties than the solution. The $\mathrm{pH}$ test results showed that the less maltodextrin used

Table 6: The concentrations of phlorotannin in four powder formulas

\begin{tabular}{llllll}
\hline Formula & $\begin{array}{l}\text { Amount of } \\
\text { extract (g) }\end{array}$ & $\begin{array}{l}\text { Amount of } \\
\text { maltodextrin (g) }\end{array}$ & $\begin{array}{l}\text { Amount in 400 g } \\
\text { of dried extract } \\
\text { powder (g) }\end{array}$ & $\begin{array}{l}\text { Phlorotannin level per g of } \\
\text { powder (mg phlorogluci } \\
\text { nol per g of powder) }\end{array}$ & $\begin{array}{l}\text { Phlorotannin level in 400 g } \\
\text { of dried liquid extract (mg } \\
\text { phloroglucinol) }\end{array}$ \\
\hline F1 & 400 & 0 & 5.91 & 6.30 & $37.10 \pm 0.12$ \\
F2 & 400 & 10 & 15.13 & 4.02 & $60.96 \pm 2.01$ \\
F3 & 400 & 20 & 25.39 & 3.20 & $80.20 \pm 1.22$ \\
F4 & 400 & 40 & 44.58 & 2.54 & 0.43 \\
\hline
\end{tabular}


Table 7: Percentage powder inhibition at a concentration of 5000 ppm

\begin{tabular}{lll}
\hline Formulation & Concentration (ppm) & Inhibition (\%) \\
\hline F1 & 5001.45 & - \\
F2 & 5000.49 & 2.06 \\
F3 & 5004.80 & 3.72 \\
F4 & 5015.00 & 4.06 \\
\hline
\end{tabular}

Table 8: Changes in water level of $\mathrm{F} 1$ and $\mathrm{F} 4$ powders during weeks $0,2,4,6$, and 8

\begin{tabular}{|c|c|c|c|c|c|c|}
\hline \multirow[t]{3}{*}{ Weeks } & \multicolumn{6}{|c|}{ Water level (\%) } \\
\hline & \multicolumn{3}{|l|}{ F1 } & \multicolumn{3}{|l|}{ F4 } \\
\hline & $4^{\circ} \mathrm{C}$ & $28^{\circ} \mathrm{C}$ & $40^{\circ} \mathrm{C}$ & $4^{\circ} \mathrm{C}$ & $28^{\circ} \mathrm{C}$ & $40^{\circ} \mathrm{C}$ \\
\hline 0 & 6.81 & 6.81 & 6.81 & 5.16 & 5.16 & 5.16 \\
\hline 2 & 5.21 & 4.77 & 4.57 & 4.92 & 4.75 & 4.34 \\
\hline 4 & 4.58 & 4.37 & 3.77 & 5.76 & 5.34 & 4.75 \\
\hline 6 & 5.74 & 5.06 & 4.38 & 6.19 & 5.56 & 4.57 \\
\hline 8 & 6.55 & 5.98 & 4.38 & 6.27 & 5.81 & 4.37 \\
\hline
\end{tabular}

in the formulation, the more basic the $\mathrm{pH}$ of the formed solution. This is because maltodextrin has a $\mathrm{pH}$ of 4-7 in solution, so its use will reduce the effect of changes in $\mathrm{pH}$ of the resulting powder.

Test of phlorotannin level of powdered S. plagyophyllum liquid extract

Among the four formulas, the highest phlorotannin content was obtained in F4 because F4 has the largest amount of maltodextrin, stabilizing the phlorotannin content of $400 \mathrm{~g}$ of liquid extract, higher than the levels presented in F1, F2, and F3. This corresponds to maltodextrin functioning as a stabilizer in the drying process.

Test of antioxidant activity of powdered S. plagyophyllum liquid extract

The greater the amount of maltodextrin used in the formulation, the higher the levels of powder and phlorotannin in the powder used and the higher the percentage inhibition that can be detected. However, there was no case reaching the $50 \%$ percent inhibition obtained from $\mathrm{F} 2, \mathrm{~F} 3$, and $\mathrm{F} 4$, which mean that $\mathrm{IC}_{50}$ could not be calculated. In $\mathrm{F} 4$, the highest detectable powder $\mathrm{IC}_{50}$ value percent was $12.05 \%$, followed by F3 of $8.78 \%$ and F2 of $6.31 \%$, while F1 did not exhibit antioxidant activity. Since the percentag inhibition of each formula differs, the antioxidant activities as reflected in the percentage inhibition of each formulation at a concentration of 5000 ppm were compared, as shown in Table 7.

Test of water level stability of powdered S. plagyophyllum liquid extract

F1 and F4 water level tests showed that F1 had a higher water level than $\mathrm{F} 4$ at all temperatures. This was due to the absence of maltodextrin from the powder. In F4, maltodextrin serves to maintain the water level of the powder during storage. Besides lowering the hygroscopicity of powder of the drying product, the use of maltodextrin may also reduce hygroscopicity during storage [15]

Test of phlorotannin stability of powdered S. plagyophyllum liquid extract

The results of the stability test showed that 8 weeks of storage significantly decreased stability in F1 compared with that in F4 (Tables 9 and 10). The highest phlorotannin levels for F1 and F4 occurred on storage at $4^{\circ} \mathrm{C}$, followed by those at a temperature of $40^{\circ} \mathrm{C}$ and at a temperature of $28^{\circ} \mathrm{C}$. For $\mathrm{F} 4$, the levels obtained were more stable due to maltodextrin protecting the phlorotannin compounds against environmental conditions (temperature, light, moisture, and oxygen).
Table 9: Changes in phlorotannin levels of $\mathrm{F} 1$ and $\mathrm{F} 4$ during weeks $0,2,4,6$, and 8 in the unit of $\mathrm{mg}$ of phloroglucinol

\begin{tabular}{llllllll}
\hline Weeks & \multicolumn{6}{l}{ Phlorotannin level (mg phloroglucinol) } \\
\cline { 2 - 4 } & $\mathbf{F 1}$ & & \multicolumn{5}{l}{$\mathbf{F 4}$} \\
\cline { 2 - 4 } \cline { 6 - 8 } & $\mathbf{4}^{\circ} \mathbf{C}$ & $\mathbf{2 8}^{\circ} \mathbf{C}$ & $\mathbf{4 0}^{\circ} \mathbf{C}$ & & $\mathbf{4}^{\circ} \mathbf{C}$ & $\mathbf{2 8}^{\circ} \mathbf{C}$ & $\mathbf{4 0}^{\circ} \mathbf{C}$ \\
\hline 0 & 37.10 & 37.10 & 37.10 & & 113.06 & 113.06 & 113.06 \\
2 & 35.25 & 28.61 & 33.88 & & 109.40 & 104.14 & 107.32 \\
4 & 34.28 & 27.14 & 29.94 & & 109.31 & 103.79 & 105.85 \\
6 & 19.38 & 17.23 & 19.06 & & 103.13 & 101.17 & 101 \\
8 & 16.86 & 15.91 & 16.22 & 101.77 & 98.70 & 100.39 \\
\hline
\end{tabular}

Table 10: Changes in phlorotannin levels of F1 and F4 during weeks $0,2,4,6$, and $8(\%)$

\begin{tabular}{|c|c|c|c|c|c|c|}
\hline \multirow[t]{3}{*}{ Weeks } & \multicolumn{6}{|c|}{ Phlorotannin level (\%) } \\
\hline & \multicolumn{3}{|l|}{ F1 } & \multicolumn{3}{|l|}{ F4 } \\
\hline & $4^{\circ} \mathrm{C}$ & $28^{\circ} \mathrm{C}$ & $40^{\circ} \mathrm{C}$ & $4^{\circ} \mathrm{C}$ & $28^{\circ} \mathrm{C}$ & $40^{\circ} \mathrm{C}$ \\
\hline 0 & 0.63 & 0.63 & 0.63 & 0.25 & 0.25 & 0.25 \\
\hline 2 & 0.60 & 0.48 & 0.57 & 0.25 & 0.23 & 0.24 \\
\hline 4 & 0.58 & 0.46 & 0.51 & 0.25 & 0.23 & 0.24 \\
\hline 6 & 0.33 & 0.29 & 0.32 & 0.23 & 0.23 & 0.23 \\
\hline 8 & 0.29 & 0.27 & 0.27 & 0.23 & 0.22 & 0.23 \\
\hline
\end{tabular}

The stability tests regarding the water level and the phlorotannin level in powder showed that the formulation with the lowest water level and the most stable phlorotannin level at 8 weeks of storage was F4 stored at $4^{\circ} \mathrm{C}$. Therefore, the powder dried with maltodextrin was better during storage than the powder dried without maltodextrin

\section{CONCLUSION}

Powder of S. plagyophyllum liquid extract with and without maltodextrin can be prepared by freeze-drying. The powder formulation with dried maltodextrin obtained with this technique can improve the stability of phlorotannin compounds during drying but does not produce good antioxidant activity. The maltodextrin-dried powder has higher phlorotannin content and lower water content during storage at $4^{\circ} \mathrm{C}$ (optimal storage temperature) than dried powder without maltodextrin.

\section{CONFLICTS OF INTEREST}

Authors declare no conflicts of interest.

\section{REFERENCES}

1. Wouthuyzen S, Herandarudewi SM, Komatsu T. Stock assessment of brown seaweeds (Phaeophyceae) along the bitung-bentena coast, North Sulawesi Province, Indonesia for alginate product using satellite remote sensing. Proc Environ Sci 2016:33;553-61.

2. Li Y, Wijesekara I, Li Y, Kim S. Phlorotannins as bioactive agents from brown algae. Process Biochem 2012;46:2219-24.

3. Vo T, Ngo D, Kim S. Marine algae as a potential pharmaceutical source for anti-allergic therapeutics. Process Biochem 2012;47:386-94.

4. Zubia M, Sophie M, Kerjean V, Le K, Stiger-pouvreau V, Fauchon M, et al. Antioxidant and antitumoural activities of some Phaeophyta from Brittany coasts. Food Chem 2009;116:693-701.

5. Mohamed S, Hashim SN, Rahman A. Seaweeds: A sustainable functional food for complementary and alternative therapy. Trends Food Sci Technol 2012;23:83-96

6. Bakowska-barczak AM, Kolodziejczyk PP. Black currant polyphenols : Their storage stability and microencapsulation. Ind Crops Prod 2011;34:1301-9.

7. Khan F, Bafna S, Gupta T, Arnold EI. Virtual screeing of potential inhibitors from herbs for the treatment of breast cancer. Asian J Pharm Clin Res 2017;10:62-7.

8. William H, Narayanan N. Comparative evaluation of antioxidant activity of substituted flavones. Asian J Pharm Clin Res 2017;10:288-91.

9. Rajendran S, Nithya G, Brindha DP, Kanakam CC. Docking antioxidant 
activity on hydroxyl (diphenyl) aceticacid and its derivatives. Asian J Pharm Clin Res 2017;10:263-5.

10. Rowe RC, Sheskey PJ, Quinn ME. Handbook of Pharmaceutical Excipients. $6^{\text {th }}$ ed. USA: Pharmaceutical Press and American Pharmacists Association; 2009

11. Pilcer G, Amighi K. Formulation strategy and use of excipients in pulmonary drug delivery. Int J Pharm 2010;392:1-19.

12. Masduqi AF, Izzati M, Prihastanti E. The effect of the drying method on seaweed chemical content Sargassum polycystum. Bul Anat Fisiol
2014;22:1-9.

13. Ye H, Zhou C, Sun Y, Zhang X, Liu J, Hu Q, et al. Antioxidant activities in vitro of ethanol extract from brown seaweed Sargassum pallidum. Eur Food Res Technol 2009;230:101-9.

14. Frecha-ferreiro S. Antioxidant compounds in edible brown seaweeds. Eur Food Res Technol 2001;231:495-8.

15. Caliskan G, Dirim SN. The effect of different drying processes and the amounts of maltodextrin addition on the powder properties of sumac extract powders. Powder Technol 2016;287:308-14 